\title{
Pengaruh Reggio Emilia Approach dalam Bermain Peran dan Bererita terhadap Kemampuan Bahasa Anak
}

\author{
AZIZAH AMAL'), MUHAMMAD AKIL MUSI2), HAJERAH ${ }^{3)}$ \\ 1), 2)Prodi Pendidikan Guru Sekolah Dasar, Universitas Negeri Makassar \\ Email: 1azizah.amal@unm.ac.id, 2)akilmusi@gmail.com, 3)hajerah123@gmail.com
}

Published Article: 27 Juni 2019

DOI: https://doi.org/10.29313/ga.v3i1.4831

\begin{abstract}
The purpose of this study was to determine the effect of applying the Reggio Emilia Approach in roleplaying and telling stories of early childhood language skills. The type of research used in the study was an experiment with a quasi-experimental design. The influence of the application of the Reggio Emilia Approach can be seen by comparing the average score obtained from the language proficiency test between the experimental groups applying the Reggio Emilia Approach in role play with the average score obtained from the control group using the Reggio Emilia Approach approach in storytelling. The conclusion is that the application of the Reggio Emilia Approach in role-playing and storytelling influences early childhood language skills.
\end{abstract}

Keywords: Reggio Emilia Approach, Role Playing, Children's Language Ability.

\begin{abstract}
Abstrak
Tujuan penelitian ini adalah mengetahui pengaruh penerapan Reggio Emilia Approach dalam bermain peran dan bercerita terhadap kemampuan bahasa anak usia dini. Jenis penelitian yang digunakan dalam penelitian adalah eksperimen dengan quasi-experimental design. Pengaruh penerapan Reggio Emilia Approach dapat dilihat dengan membandingkan rata-rata perolehan skor hasil tes kemampuan bahasa antara kelompok eksperimen yang menerapkan Reggio Emilia Approach dalam bermain peran dengan rata-rata perolehan skor hasil tes kelompok kontrol yang menggunakan pendekatan Reggio Emilia Approach dalam bercerita. Hasil kesimpulannya adalah penerapan Reggio Emilia Approach dalam bermain peran dan bercerita berpengaruh terhadap kemampuan bahasa anak usia dini.
\end{abstract}

Kata Kunci: Reggio Emilia Approach, Bermain Peran, Kemampuan Bahasa Anak. 
Golden Age: Jurnal Pendidikan Anak Usia Dini, Volume 3 Nomor 1 (Juni 2019)

AZIZAH AMAL, MUHAMMAD AKIL MUSI, HAJERAH/Pengaruh Reggio Emilia Approach dalam Bermain Peran dan Bercerita terhadap Kemampuan Bahasa Anak

\section{Pendahuluan}

Pendidikan anak usia dini merupakan upaya untuk menstimulasi, membimbing, mengasuh dan memberikan kegiatan pembelajaran yang mampu menghasilkan kemampuan dan keterampilan anak. Pendidikan anak usia dini merupakan wadah bagi anak usia 0-6 tahun untuk mengembangkan potensi pada diri merekabaik potensi fisik, kognitif, bahasa maupun sosial emosional.

Pendidikan anak usia dini harus berlandaskan pada kebutuhan anak, yang disesuaikan dengan nilai-nilai yang dianut di lingkungan sekitarnya, sesuai dengan tahap perkembangan fisik dan psikologis anak, dilaksanakan dalam suasana bermain yang menyenangkan serta dirancang untuk mengoptimalkan potensi anak. Hal ini sejalan dengan Permen 137 tahun 2014 Pasal 13 yang menyatakan bahwa pelaksanaan pembelajaran di taman kanak-kanak dilakukan melalui bermain secara interaktif, inspiratif, menyenangkan, kontekstual dan berpusat pada anak untuk berpartisipasi aktif serta memberikan keleluasaan bagi prakarsa, kreativitas, dan kemandirian sesuai dengan bakat, minat, dan perkembangan fisik serta psikologis anak.

Pendekatan pembelajaran yang mendasar dalam pendidikan anak usia dini adalah pendekatan perilaku dan pendekatan perkembangan. Pendekatan perilaku menganggap bahwa konsepkonsep tidaklah berasal dari dalam diri anak dan tidak berkembang secara spontan. Sedangkan pendekatan perkembangan memberikan kerangka untuk memahami dan menghargai pertumbuhan alami anak-anak usia dini dan menganggap bahwa anak-anak usia dini adalah pembelajar aktif yang secara terus menerus mendapatkan informasi mengenai dunia lewat permainan. Salah satu pendekatan perkembangan adalah Reggio Emilia Approach (REA) yang menganggap anak-anak adalah pembelajar kompeten sehingga model kurikulum yang dijalankan bisa diarahkan oleh anak-anak itu sendiri. Guru mengikuti minat anakanak dan memberikan instruksi-instruksi standar. REA sangat percaya bahwa anak-anak belajar melalui interaksi dengan teman, orangtua, guru serta interaksi dengan lingkungan tempat
belajarnya.Pendekatan REA ini berkomitmen "menciptakan kondisi pembelajaran yang mendorong dan memfasilitasi anak untuk membangun kekuatan berpikirnya sendiri melalui penggabungan seluruh bahasa ekspresif, komunikatif, dan kognitifnya" (Rinaldi, 2006, Kelemen, 2013, Vecchi, 2010).

Metode atau pendekatan pendidikan, terutama untuk anak usia dini, yang berbeda dari pendekatan lainnya, yaitu Pendekatan REA ini berkomitmen "menciptakan kondisi pembelajaran yang akan mendorong dan memfasilitasi anak untuk membangun kekuatan berpikirnya sendiri melalui penggabungan seluruh bahasa ekspresif, komunikatif, dan kognitifnya" (Hewet, 2011, Vecchi, 2010).

Anak-anak didorong untuk menggambarkan pemahaman mereka melalui salah satu dari bahasa simbolik, termasuk gambar, patung, bermain drama, dan menulis. Mereka bekerja bersamasama menyelesaikan masalah-masalah yang timbul. Guru memfasilitasi dan kemudian mengamati perdebatan mengenai sejauh mana anak mampu menyelesaikan masalah. Revisi gambar (dan ide) dilakukan jika perlu, dan guru membiarkan anak-anak untuk mengulangi kegiatan dan memodifikasi setiap karya lain dalam tujuan kolektif pemahaman topik yang lebih baik. Guru terlibat dalam proses eksplorasi dan evaluasi, dan memperhatikan semua hasil perkembangan anak dalam menyelesaikan masalah sesuai pemahaman mereka.(Morrison, 2012, Kelemen,2013)

Inti kurikulum Reggio Emilia adalah perencanaan proyek sebagai hasil dari ketertarikan anak pada suatu hal.Proyek ini tumbuh dari pengalaman pertama yang direncanakan oleh guru untuk membantu anak-anak mengeksplorasi adat budaya mereka atau lingkungan fisik sekitar mereka atau hasil dari kejadian spontan seperti ide anak atau pertanyaan pada guru.Hampir setiap pengalaman yang membangkitkan minat anak dapat menjadi dasar proyek.Proyek dilakukan secara mendalam dan mendetail, menggunakan variasi dalam metode penyelidikan dan sebuah gambaran pilihan dan sebuah bentuk grafik. Untuk melengkapi proses investigasi/penyelidikan melalui 
Golden Age: Jurnal Pendidikan Anak Usia Dini, Volume 3 Nomor 1 (Juni 2019)

AZIZAH AMAL, MUHAMMAD AKIL MUSI, HAJERAH/Pengaruh Reggio Emilia Approach dalam Bermain Peran dan Bercerita terhadap Kemampuan Bahasa Anak

proyek jangka panjang ini adalah kreativitas anak dalam menggunakan bahan untuk menunjukkan dan mengkomunikasikan pembelajaran mereka, menggunakan "hundred languages". Pada setiap langkah aktivitas, guru-guru mengobservasi, mendiskusikan dan menafsirkan bersama hasil observasi mereka, yang selanjutnya membuat pilihan-pilihan baru untuk ditawarkan pada anakanak. Dengan mendiskusikan dalam kelompok dan menilik ulang pengalaman-pengalaman dan ide-ide anak-anak akan tumbuh dengan pemahaman mereka. Beberapa fitur kunci dari awal masa kanakkanak dalam program REA. (Rinaldi, 2006, Kelemen, 2013, Morrison, 2012).

Salah satu bidang pengembangan dalam pertumbuhan kemampuan dasar di taman kanakkanak adalah pengembangan bahasa. Bahasa memungkinkan anak untuk menerjemahkan pengalaman ke dalam simbol-simbol yang dapat digunakan untuk berkomunikasi dan berpikir.Bahasa erat sekali kaitannya dengan perkembangan kognitif.Bahasa merupakan alat untuk mengekspresikan ide dan bertanya, dan bahasa juga menghasilkan konsep dan kategorikategori untuk berpikir. (Brown, 2000, Fein, 1978, Masito, 2005)

Bahasa merupakan alat untuk berkomunikasi.Melalui bahasa manusia dapat berinteraksi dan berkomunikasi, mengemukakan hasil pemikirannya dan dapat mengekspresikan perasaannya.Dengan bahasa orang dapat membuka cakrawala berfikir dan mengembangakan wawasannya.Anak-anak belajar bahasa melalui interaksi dengan lingkungannya baik lingkungan rumah, sekolah, atau masyrakat.Di sekolah anak belajar bahasa melalui interaksi dengan guru, teman sebaya dan orang dewasa lainnya. Guru atau pendidik anak usia dini perlu memahami tentang perkembangan dan pengembangan bahasa anak. (Otto, 2015, Brown, 2000, Hurlock, 1995, Owens, 2012)

Pernyataan-pernyataan di atas dapat dikatakan bahwa bahasa merupakan suatu sistem dan urutan kata-kata yang digunakan untuk berkomunikasi dengan orang lain.
Hasil penelitian (Dougherty, 2003) telah membuktikan bahwa pengembangan kemampuan menggunakan bahasa merupakan langkah yang penting untuk mengembangkan kemampuan berlatih dan berpikir dan akan mempunyai dampak yang nyata dalam seluruh pengalaman pendidikan anak usia dini. Hal ini dimungkinkan karena kemampuan menggunakan bahasa merupakan suatu hal yang perlu guna mempelajari keterampilan penting dalam disiplin ilmu yang lain yang juga akan mendukung prestasi di sekolah. Ketika seorang anak memasuki lingkungan sekolah, dia harus mampu memahami orang lain dan untuk dapat mengekspresikan pendapat pribadinya secara oral agar nantinya dia dapat meraih kesuksesan dalam mengerjakan tugastugas sekolah seperti membaca dan menulis. (Fisher, 1998, Owen, 2012)

Metode dan strategi untuk mencapai kompetensi anak didik adalah metode bermain peran dan kegiatan bercerita. Kedua metode ini lebih menitikberatkan keaktifan anak didik dalam proses pembelajaran.(Moeslichatoen, 2004, Masito, 2005)

Metode bermain peran dapat dilakukan dengan cara bermain peran makro dan bermain peran mikro, dimana bermain peran makro anak akan memerankan peran-peran sosial yang ada dilingkungan sekitar anak. Sementara bermain peran mikro, anak menggunakan alat seperti boneka, boneka tangan, wayang dan lain sebagainya untuk memerankan peran-peran sosial tersebut. Sehingga bermain peran makro maupun bermain peran mikro terlihat jelas akan lebih mengaktifkan anak dalam proses pembelajaran terutama dalam hal kemampuan anak dalam berbahasa baik kemampuan bahasa reseptif maupun kemampuan bahasa ekspresif. (Jan, 1999, Rogers, 2009, White, 2008, Hurlock, 1995)

Selain bermain peran, kegiatan bercerita juga merupakan salah satu kegiatan pembelajaran yang bisa mengembangkan kemampuan berbahasa anak, baik bahasa reseptif maupun bahasa ekspresif. Tetapi kegiatan bercerita yang selama ini dilakukan di taman kanak-kanak lebih banyak digunakan untuk mengembangkan kemampuan 
Golden Age: Jurnal Pendidikan Anak Usia Dini, Volume 3 Nomor 1 (Juni 2019)

AZIZAH AMAL, MUHAMMAD AKIL MUSI, HAJERAH/Pengaruh Reggio Emilia Approach dalam Bermain Peran dan Bercerita terhadap Kemampuan Bahasa Anak

bahasa reseptif anak. Ini dilihat dari kegiatan bercerita itu hanya dilakukan oleh guru dan anak didik duduk mendengarkan cerita tersebut sampai selesai.(Rahim, 2012, Dunst, 2012, Isbell, 2004, Lenox, 2000, Moeslichatoen, 2004)

Berdasarkan latar belakang di atas, maka yang menjadi masalah dalam penelitian ini adalah: 1) Bagaimana pengaruh Reggio Emilia Approach dalam bermain peran terhadap kemampuan bahasa anak? 2) Bagaimana pengaruh Reggio Emilia Approach dalam bercerita terahdap kemampuan bahasa anak? 3) Apakah terdapat perbedaan kemampuan berbahasa antara kelompok anak yang melakukan REA dalam bermain peran dan REA dalam bercerita?

\section{Metode Penelitian}

Jenis penelitian yang digunakan dalam penelitian ini adalah quasi-experimental design atau eksperimen semu.Penggunaan jenis penelitian ini berdasarkan sifat populasi, yakni anak didik yang tidak tetap dan bervariasi.Penelitian ini mengkaji dua variabel, yaitu pendekatan saintifik berbasis contextual teaching and learning sebagai variabel bebas atau yang memengaruhi dan kemampuan sains sebagai variabel terikat atau yang dipengaruhi.Desain penelitian yang di gunakan yaitunonequivalent control group designdimana pengukuran dilakukan melibatkan dua kelompok, yaknikelompok eksperimen dan kelompok kontrol. Adapun desain penelitian dapat digambarkan sebagai berikut (Sugiyono, 2013):

\begin{tabular}{|lll|}
\hline $\mathrm{O}_{1}$ & $\mathrm{X}_{1}$ & $\mathrm{O}_{2}$ \\
$\mathrm{O}_{3}$ & $\mathrm{X}_{2}$ & $\mathrm{O}_{4}$ \\
\hline
\end{tabular}

\section{Keterangan :}

$\mathrm{O}_{1}$ dan $\mathrm{O}_{3}$ : Pengukuran pertama (awal) sebelum subyek diberikan perlakuan REA dalam bermain peran dan REA dalam bercerita

$X_{1}$ dalam bermain peran

$\mathrm{X}_{2}$ dalam bercerita

$\mathrm{O}_{2}$

: Pengukuran kedua setelah subjek diberikan perlakuan REA dalam

bermain peran

$\mathrm{O}_{4}$

: Pengukuran kedua setelah subjek diberikan perlakuan REA dalam

Bercerita

Variabel dalam penelitian ini terdiri dari (1) variabel bebas yakni REA dalam bermain peran dan REA dalam kegiatan bercerita (2) variabel terikat yakni kemampuan bahasa anak dalam hal kemampuan bahasa reseptif dan kemampuan bahasa ekspresif.

Bahasa merupakan landasan seorang anak untuk mempelajari hal-hal lain. Sebelum dia belajar pengetahuan-pengetahuan lain, dia perlu menggunakan bahasa agar dapat memahami dengan baik. Anak akan dapat mengembangkan kemampuannya dalam bidang pengucapan bunyi, menulis, membaca yang sangat mendukung kemampuan keaksaraan di tingkat yang lebih tinggi.

Kemampuan berbahasa pada anak usia dini terbagi atas kemampuan memahami pembicaraan orang lain (receptive language) dan kemampuan mengemukakan pendapat (expressive language). Bahasa merupakan alat bergaul. Oleh karena itu, penggunaan bahasa menjadi efektif sejak seseorang memerlukan berkomunikasi dengan orang lain. Sejak seorang bayi mulai berkomunikasi dengan orang lain, sejak itu pula bahasa diperlukan.

\section{Pembahasan}

Hasil penelitian menunjukkan bahwa rata-rata kemampuan bahasa kelompok Bercerita lebih 
Golden Age: Jurnal Pendidikan Anak Usia Dini, Volume 3 Nomor 1 (Juni 2019)

AZIZAH AMAL, MUHAMMAD AKIL MUSI, HAJERAH/Pengaruh Reggio Emilia Approach dalam Bermain Peran dan Bercerita terhadap Kemampuan Bahasa Anak

rendah dari kelompok bermain peran.Nampak secara matematis bahwa kelompok bermain peran lebih tinggi dari pada kelompok bercerita dalam kemampuan bahasa.Dengan demikian dapat disimpulkan bahwa terdapat perbedaan yang signifikan antara kemampuan bahasa kedua kelompok yaitu kelompok bercerita dan kelompok bermain peran.

Pendekatan REA berkomitmen "menciptakan kondisi pembelajaran yang akan mendorong dan memfasilitasi anak untuk membangun kekuatan berpikirnya sendiri melalui penggabungan seluruh bahasa ekspresif, komunikatif, dan kognitifnya baik dalam kegiatan bercerita maupun dalam kegiatan bermain peran. Pendekatan Reggio Emilia percaya bahwa anak usia dini belajar melalui interaksi dengan orang lain, termasuk orangtua, dan masyarakat. Pendekatan Reggio Emilia melihat anak-anak mempunyai sikap berdaya saing, kreatif, ingin tahu, imaginatif, intensif dan mempunyai keinginan untuk berinteraksi dan berkomunikasi dengan orang lain.

Hasil penelitian menunjukkan bahwa kemampuan bahasa pada kelompok bercerita lebih rendah, hal ini memberikan makna bahwa kegiatan bercerita selalu dilakukan dan anak merasa bosandengan cerita yang selalu diulangulang.Meskipun demikian mereka memahami bahwa metode cerita dipandang mampu mengembangkan bahasa anak.Metode bercerita ialah metode yang mengisahkan suatu peristiwa atau kejadian kepada peserta didik.Kejadian atau peristiwa tersebut disampaikan melalui tutur kata, ungkapan dan mimik wajah yang unik. Metode bercerita berarti penyampaian cerita dengan cara bertutur yang membedakan antara bercerita dengan metode penyampaian cerita lain adalah lebih menonjol aspek teknis penceritaan lainnya. Bercerita adalah salah satu strategi pembelajaran dimana penyampaiannya melalui tutur kata secara lisan dengan menceritakan kisah atau suatu peristiwa dan informasi tanpa meninggalkan tujuan dari pembelajaran tersebut.

Metode bercerita merupakan salah satu metode yang dilakukan dalam menyampaikan informasi, peristiwa atau kejadian secara lisan dengan membawakan cerita kepada anak tanpa meninggalkan tujuan dari pembelajaran tersebut.Ada beberapa hal yang harus diperhatikan dalam metode bercerita.Cerita yang disampaikan harus dikemas secara menarik sehingga dapat memberi kesempatan anak untuk bertanya dan menanggapi isi dari cerita tersebut.

Menurut Rahayu (2013: 80) yang menjelaskan bahwa cerita adalah "Uraian, gambaran, atau deskripsi, tentang peristiwa atau kejadian tertentu".Sedangkan menurut Hidayat (Rahayu, 2013: 80) yang mengatakan bahwa bercerita adalah "Merupakan aktivitas menuturkan sesuatu yang mengisahkan tentang perbuatan, pengalaman, atau kejadian yang sungguh-sungguh yang terjadi maupun hasil rekaan".

Dengan demikian kegiatan bercerita sebaiknya dilakukan berdasarkan perkembangan anak dan cerita yang disampaikan berdasarkan pemikiran anak yang akan mendengarkan cerita, sehingga anak tidak bosan dan selalu fokus pada kegiatan bercerita yang dilaksanakan oleh guru.

Selanjutnya hasil penelitian menunjukkan bahwa kemampuan bahasa pada kelompok bermain peran lebih tinggi.Hal ini dikarenakan anak lebih senang bermain peran dibanding mendengarkan cerita.Karena bermain peran menyebabkan anak terlibat langsung dalam kegiatan yang dilakukan.Selama pembelajaran berlangsung, setiap pemeranan dapat melatih sikap empati, simpati, rasa benci, marah, senang, dan peran lainnya.Pemeranan tenggelam dalam peran yang dimainkannya sedangkan pengamat melibatkan dirinya secara emosional dan berusaha mengidentifikasikan perasaan dengan perasaan yang tengah bergejolak dan menguasai pemeranan.

Bermain peran dalam pembelajaran merupakan usaha untuk memecahkan masalah melalui peragaan, serta langkah-langkah identifikasi masalah, analisis, pemeranan, dan diskusi.Untuk kepentingan tersebut, sejumlah peserta didik bertindak sebagai pemeran dan yang lainnya sebagai pengamat.Seorang pemeran harus mampu menghayati peran yang dimainkannya.Melalui peran, peserta didik 
Golden Age: Jurnal Pendidikan Anak Usia Dini, Volume 3 Nomor 1 (Juni 2019)

AZIZAH AMAL, MUHAMMAD AKIL MUSI, HAJERAH/Pengaruh Reggio Emilia Approach dalam Bermain Peran dan Bercerita terhadap Kemampuan Bahasa Anak

berinteraksi dengan orang lain yag juga membawakan peran tertentu sesuai dengan tema yang dipilih.

Saat bermain peran ini bisa menjadi ajang belajar bagi mereka, baik belajar membaca, berhitung, mempelajari proses/alur dalam mengerjakan sesuatu, mengenal tata tertib/tata cara di suatu tempat, yang semua ada dalam kehidupan kita. Tentu saja kita hanya cukup memberikan informasi sebelum mereka mulai bermain, dan atau lebih baik kalo kita terlibat dalam permainan tersebut agar kita bisa menggali imaginasi dan mengenalkan informasi yang ingin kita kenalkan.

Tujuan metode bermain peran yaitu dapat melatih daya tangkap, berbicara dengan lancar, konsentrasi anak agar dapat lebih fokus, membuat kesimpulan, mengembangkan kognitif anak, menciptakan suasana yang menyenangkan, mengembangkan keterampilan dan sikap dalam memecahkan masalah yang dihadapi. Tujuan tersebut diharapkan akan memudahkan anak dalam mengembangkan kemampuan berbahasa anak usia dini dengan cara menerapkan metode bermain peran.

Menurut Piaget, awal main peran dapat menjadi bukti perilaku anak. Piaget menyatakan bahwa bermain peran ditandai oleh penerapan cerita pada objek dan mengulang perilaku menyenangkan yang diingatnya.Piaget menyatakan bahwa keterlibatan anak dalam bermain peran dan upaya anak mencapai tahap yang lebih tinggi dibandingkan dengan anak lainnya disebut sebagai collective symbolism.la juga menerangkan percakapan lisan yang anak lakukan dengan diri sendiri sebagai idiosyncratic soliloquies.

Dengan demikian bermain peran atau bermain drama merupakan permainan yang bersifat reproduktif. Melalui kegiatan bermain anak dapat meningkatkan kemampuan berbahasa anak dengan cara mendengarkan beraneka bunyi, mengucapkan suku kata dan berbicara sesuai dengan tata bahasa Indonesia. Sedangkan bercerita merupakan kegiatan menyampaikan amanat atau pesan melalui sejumlah kata-kata, dengan cara yang menarik melalui media atau nonmedia. Dalam bercerita ada keterampilan menyimak dan berbicara sebagai unsur yang penting dalam komunikasi antara guru dan murid. Melalui berbicara guru atau murid menyampaikan informasi melalui suara dan bunyi bahasa, sedangkan dalam menyimak anak didik akan mendapat informasi melalui ucapan atau suara bicara yang diterimanya dari guru.

\section{Daftar Pustaka}

Arifin, Imron. 2009. KepemimpinanKepala PAUD dalamMengimpelemetasikanPembelajaranPA UD.Yogjakarta: Aditya Media.

Armstrong, Thomas. 2000. Multiple Intelligences in the Classroom $2^{\text {nd }}$ Edition:Association for Supervision and Curricullum Development. Alexandria, Virginia USA.

Berk, Laura E. 2006.Child Development, Seventh Edition. USA: Pearson.

Bobby, A. 1994.Ages and Stages Development Milestone for Receptive and Expressive Language Acquisition.http: //www. Members.tripod.com/Caroline_Bowen/develz. $\mathrm{Htm}$. Diakses tanggal 6 Februari 2017.

Brown, H. Douglas.2000. Principles of Language Learning and Teaching.San Fransisco State University: Longman.

Chaplin, J.P. 1972. Dictionary of Psycology. New York: Dell Publishing Co. Inc.

Degeng, I Nyoman Sudana. 1988. IlmuPengajaran: Taksonomi Variable. Jakarta: Depdikbud, Direktorat Jenderal Pendidikan Tinggi PPLPTK.

Dominic, Gullo F. 2005. Understanding Assessment and Evaluation in Early Childhood Education. New York: Teachers College, Columbia University.

Dougherty, Dorothy P. 2003. BagaimanaBerbicaradenganBayiAnda:

PanduanMemaksimalkanKecakapanBelajarda nBahasaAnakAnda. Jakarta: Prestasi Pustaka. 
Golden Age: Jurnal Pendidikan Anak Usia Dini, Volume 3 Nomor 1 (Juni 2019)

AZIZAH AMAL, MUHAMMAD AKIL MUSI, HAJERAH/Pengaruh Reggio Emilia Approach dalam Bermain Peran dan Bercerita terhadap Kemampuan Bahasa Anak

Eva, Essa L. 2009. Introduction to Early Childhood Education $6^{\text {th }}$ edition, Annotated Student's Edition. USA: Wadsworth.

Fein, Greta G. 1978. Child Development. New Jersey: Prentice Hall, Inc.

Fleetham, Mike. 2006. Multiple Intelligence: In Practice Enhancing Self-Esteem and Learning In The Classroom: An imprint of the Continuum International Publishing Group Ltd First Published.

Fung, Daniel dan Cai Yi-Ming. 2003. MengembangkanKepribadianAnakdenganTep at: PetunjukMengasuhAnakUsia 0-6 Tahun. Jakarta: Prestasi Pustaka.

Hartati, Sofia. 2007. How To Be A Good Teacher and To Be a Good Mother: Seri Panduan PAUD. Jakarta ; Enno Media..

Handini, Myrnawati Crie. 2012. MetodologiPenelitianUntukPemula. Jakarta : FIP Press.

Hewet, Valarie Mercilliot. 2011. Examining the Reggio Emilia Approach to Early Childhood Education. Early Childhoos Education Journal, Vol 29 No. 2, Winter 2001.

Hurlock, B. Elizabeth. 1995. PerkembanganAnak: Jilid 1. Jakarta: Erlangga.

-..... 1995. PerkembanganAnak: Jilid 2. Jakarta: Erlangga.

Isbell, Sobol, Lindauer and Lowrence. 2004. The Effect of Storytelling andStiry Reading on the Oral Language Complexity and Story Comprehension of Young Children. Early Childhood Education Journal, Vol. 32 No. 3, December 2004.

Jan, Allen \& Catron, Carol E. 1999. Early Childhood Curriculum A Creative-Play Model, Second Edition, Merril, an imprint - Hall Upper Saddle River. New Jersey: Columbus, Ohio.

Jensen, Eric Super. 2009. Teaching Fourth Edition. United States of America.

Joyce, Bruce, Marsha Weil dan Emily Calhoun. 2009. Models Teaching: Model-Model Pengajaran. Yogjakarta: PustakaPelajar.

Joyce, Weil B. 2011. Models of Teaching. BostonLondon: Allyn and Bacon.
Kelemen, Gabriela. 2013. The Reggio Emilia Method, A Modern Approach of Preschool Education. Journal Plus Education, ISSN: 1842-077 X, E-ISSN (online) 2068-1151 Vol. X (2013) N0. 1 pp. 87-92.

Latif $\quad 2013$. OrientasiBaruPendidikanAnakUsiaDini.

TeoridanAplikasi. Jakarta: Kencana Media Group.

Lenox, Mary F. 2000. Storytelling for Young Children in a Multicultural World. Early Childhood Education Journal, Vol. 28 No. 2. 2000.

Masito, dkk.2005. MetodePengembanganBahasa. Jakarta: Pusat Pembinaan Bahasa.

Moeslichatoen.2004. MetodePengajaran Di Taman Kanak-Kanak. Jakarta: Rineka Cipta.

Morrison, George S. 2012. Dasar-dasar Pendidikan Anak Usia Dini (PAUD). Edisi Kelima. Jakarta: PT. Indeks.

Mulyadi, Seto. 2004. Bermain\&Kreativitas, UpayaMengembangkanKreativitasAnakMelal uiKegiatanBermain. Jakarta: Papas Sinar Sinanti,.

Musfiroh, Tadkiroatun. 2008a. CerdasMelaluiBermain: Cara Mengasah Multiple Intelligence PadaAnakUsiaDini.

- 2008b. Cerita Untuk Anak Usia Dini. Yogyakarta: Tiara Wacana.

Rahman, Hibana S. 2002. KonsepDasarPendidikanAnakUsiaDini. Yogyakarta: PGTKI Press.

Rinaldi, Carlina. 2006. In Dialogue with Reggio Emilia: Listening, Researching and Learning. New York: Routledge.

Rogers, Sue and Evans, Julie. 2009. Inside Role Play in Early Childhood Education: Researching Young Children's Perspectives. American Journal of Play. New York: Routledge, 152 pp. ISBN: 9780415404976.

Saracho, Olivia N. 1984. Countruction and Validation the Play Raing Scale Early Child Development and Care, Vol.17 pp. 199-230.

Santrock, John W. 2004. PerkembanganAnakJilid 2. Jakarta: Penerbit Erlangga. 
2009. Education Psikologi. Jakarta:

Salemba Humanika.

Santoso, Soegeng. 2011. Konsep PAUD

MenurutPendirinya 1.Jakarta UNJ.

2011. Konsep

PAUD

MenurutPendirinya 2.Jakarta UNJ.

Slavin, Robert E. 2008.PsikologiPendidikan; TeoridanPraktek. Jakarta: PT Macana Jaya Cemerlang.

Sudjana. 1994. DesaindanAnalisisEksperimen. Bandung: Tarsito.

-...2007.MetodeStatistika. Bandung:

Tarsito.

Sunartodan B. Agung Hartono. 2002. PerkembanganPesertaDidik. Jakarta: PT. Rineka Cipta.

Suparman, Atwi. 1997. Model-Model PembelajaranInteraktif. Jakarta: STIA LAN Press.

Suryana, Dadan. 2014. Kurikulum Pendidikan Anak Usia Dini Berbasis Perkembangan Anak. Jurnal Pesona Dasar, Vol. 1 No. 3, April 2014. ISSN: 2337-9227

Tedjasaputra, Mayke. 2001. Bermain, Mainan, danPermaainan:

UntukPendidikanAnakUsiaDini. Jakarta. Grasindo.

Vecchi, Vea. 2010. Art and Creativity in Reggio Emilia: Exploring the Role and Potential of Ateliers in Early Childhood Education. New York: Routledge.

Wooflk, Anita E dan Lorraine McCune-Nicolich. 2004. MengembangkanKepribadian Dan KecerdasanAnakAnak(PsikologiPembelajaran I)terjemahan M. Khairui Anam. Depok: Inisiasi Press.

Yusuf, Syamsu. 2002.

PsikologiPerkembanganAnakdanRemaja.

Bandung: PT. Remaja Rosdakarya.

Zulkifli. 2001. PsikologiPerkembangan. Bandung: PT. Remaja Rosdakarya. 